\title{
ARQUIVOS DA MEMÓRIA - OU SEU DIÁRIO EM BOAS MÃOS
}

ARCHIVES OF MEMORY - OR YOUR DIARY IN GOOD HANDS

Marilia Santanna Villar

Universidade Federal do Rio de Janeiro

Rio de Janeiro, Brasil

\section{Resumo}

O presente artigo visa a apresentar como os arquivos de autobiografia contemporânea surgem e como podem ajudar no estudo da memória e do esquecimento, matéria-prima dos escritos do eu. $\mathrm{O}$ gênero autobiográfico que ganha força com publicações como As Confissóes de Jean-Jacques Rousseau mostra-se cada vez mais atual. A luta contra o esquecimento, o desejo de fazer ouvir sua própria voz, de registrar sua existência, deixando para a posteridade um testemunho do que foi sua vida, nunca foi tão atual como nesse início de século XXI, em que diariamente há pessoas partilhando com conhecidos e desconhecidos sua vida pessoal. Blogs, Facebook, páginas profissionais repletas de fotos e testemunhos se multiplicam na web. Certamente, são muitos os que fazem dessas redes sociais uma válvula de escape de sua realidade e acabam criando personalidades e vidas que pouco têm a ver com o que realmente estão vivendo. As fotos são com boa resolução e tiradas em locais "fotogênicos", por vezes retrabalhadas no Photoshop. Mas, em meio a todo esse afá de publicaçóes imediatas, ainda existem associaçôes que se preocupam com a autobiografia contemporânea escrita nos moldes tradicionais. No presente artigo, voltamo-nos para uma análise da APA francesa, para mostrar o lugar que ocupam os escritos autobiográficos em suporte papel na era das mídias digitais.

Palavras-chave: arquivos autobiográficos; memória; autobiografia não literária.

\section{Abstract}

This article aims to present how the archives of modern autobiography begin and how they can help the studies of memory and forgetfulness, the raw material for the writings about the self. The autobiographical gender becomes stronger after Jean-Jacques Rousseau's Confessions and is now more and more common. The struggle against the forgetfulness, the desire of being heard, of registering one's existence, leaving behind one's own testimony of what has been one's life, this has never been so current

\section{Résumé}

Cet article a comme but de présenter comment les archives de l'autobiographie contemporaine surgissent et comment il peuvent aider l'étude de la mémoire et de l'oubli, matière-première des écritures du moi. Le genre autobiographique qui devient plus fort avec la publication des Confessions de Jean-Jacques Rousseau se montre très actuel. La lutte contre l'oubli, le désir de faire entendre sa propre voix, d'enregistrer son existence, laissant à la postérité un témoignage de ce qu'a été sa vie, ceci n’a jamais été aussi actuel 
as it is now in the beginning of the $21^{\text {st }}$ century, when everyday people are sharing their personal life with friends as well as with people they don't know. Blogs, Facebook, professional pages filled with photos get multiplied on the net. There are many who transform the social networks into outlets for reality and build up personalities and lives which have little to do with what they actually live. The photos have a good resolution and are taken at "photogenic" places, edited with Photoshop. But, in the middle of these millions of instantaneous publications, there are associations which are still concerned about the contemporary autobiography written in traditional molds. In this article, we develop an analysis of the APA (Association pour l'Autobiographie) to investigate the role played by autobiographical writings on paper in the digital era.

Keywords: autobiographical archives; memory; non-literary autobiography. qu'au début de ce XXIe siècle, où tous les jours il y a des personnes qui partagent leur vie personnelle avec des inconnus et des personnes de leur connaissance. Les blogs, le Facebook, les pages professionnelles remplies de photos se multiplient sur internet. Il y en a beaucoup qui font des réseaux sociaux un exutoire pour fuir leur réalité et créent des personnalités et des vies qui ont peu à voir avec ce qu'ils vivent effectivement. Les photos ont une bonne résolution et sont prises dans des endroits "photogéniques", retravaillées sur Photoshop. Mais, au milieu de cette multitude de publications immédiates, il y a encore des associations qui se préoccupent de l'autobiographie contemporaine écrite de façon traditionnelle. Dans cet article, nous nous tournons vers une analyse de l'Association pour l'Autobiographie française pour enquêter sur la place qu'occupent les écrits autobiographiques en support papier à l'ère du numérique.

Mots-clés: archives autobiographiques; mémoire; autobiographie non-littéraire.

Mais on arrange aisément les récits du passé que personne ne connaît plus comme ceux des voyages dans les pays où personne n'est jamais allé.

(Proust. Le Temps retrouvé)

Esquecer não é apenas não lembrar. Esquecer é, depois de Freud, entendido como um processo muito mais sério, esquecer torna-se, para além do simples apagamento de memórias, repressão e recalque. Quando, diante da atual situação política de nosso país, ouvimos a célebre frase "o povo brasileiro não tem memória”, é a um esquecimento voluntário ou involuntário que se alude? $\mathrm{O}$ povo brasileiro escolhe não se lembrar dos problemas vividos na política e acredita agora totalmente no que lhe é dito pelos governantes, ou os brasileiros náo escolheram esquecer, mas, simplesmente mais privi- 
legiando talvez o lazer, não exercitam sua memória e votam acreditando em promessas daqueles que já deram provas de que não as cumprem? A memória é muito estudada, mas pouco compreendida. Assusta-nos o porquê do esquecimento. Assusta-nos um país que se esquece de seus políticos ou um idoso que dá sinais de Alzheimer. O esquecimento é terrível. Talvez o medo de esquecer dos outros. Ou pior: de que se esqueçam de nós. É desse medo que tantos parecem querer fugir todos os dias. Esquecer não é, certamente, apenas não lembrar.

E, por medo do esquecimento, na tentativa de registrar o que vivemos, muitos buscam a escrita. Sim, todos fazemos isso em situaçóes diferentes: o profissional que anota em sua agenda seus muitos compromissos para poder honrá-los e comparecer à hora e local combinados; a dona de casa que faz a lista de compras para o mercado e o estudante que anota o trabalho de casa. Todos tomamos nota em nossas agendas - de papel ou eletrônicas, em aplicativos de última geraçáo, no pedaço de papel de rascunho ou mesmo na palma da mão, por falta de suporte melhor - das atividades que temos de fazer. Alguns, entretanto, vão mais longe e escrevem sua autobiografia. As memórias, classicamente entendidas como texto escrito ao final de uma vida longa e por um grande escritor, são exatamente essa busca. Quando Philippe Lejeune escreve seu primeiro trabalho sobre a autobiografia, em sua tese de Doutorado L'Autobiographie en France, ele situa o nascimento da autobiografia moderna como uma consequência do romance autobiográfico do século XVIII. ${ }^{1}$

L'autobiographie moderne n'est donc pas née en rupture avec la biographie traditionnelle (d'ailleurs même après Rousseau et jusqu'à aujourd'hui, il continue à y avoir des autobiographies qui se comportent comme de simples biographies), mais simplement à la suite de l'apparition d'une nouvelle forme biographique (le roman autobiographique). (LEJEUNE, 1971: 46)

Santo Agostinho em suas Confissóes escreve sua conversão. É uma autobiografia que se propóe a apontar os pecados de sua vida antes de abraçar o Catolicismo, uma autobiografia com fins didático-religiosos: mostrar o caminho do erro e o caminho da conversão. Assim como o Bispo de Hipona, tantos outros santos foram levados - muitas vezes por seus confessores - a redigirem um depoimento autobiográfico.

As Confissöes, portanto, não são um livro de reminiscências. São um voltar-se angustiado para o passado. O tom de urgência é inconfundível. "Permiti-me, eu Vos imploro, concedei-me percorrer em minha memória as espirais passadas de meus erros [...]". (BROWN, 2005: 201)

\footnotetext{
${ }^{1}$ Em seus textos posteriores, Lejeune vai rever muitas das questôes que ele havia desenvolvido em sua tese de doutorado e no seu livro mais conhecido - e também mais criticado -, Le Pacte Autobiographique.
} 
Mas Lejeune fala do século XVIII e, ao tratarmos da autobiografia desse período na França, o autor que certamente nos vem à mente é Rousseau com suas Confissóes. Rousseau não confessa como os santos. Se ele conta - e sua proposta é exatamente esta - mesmo os episódios mais embaraçosos, não é com um objetivo religioso, mas para justificar suas escolhas e deixar ele próprio uma narrativa que o explique, tentando escapar, assim, das conjecturas que inevitavelmente cercam o homem célebre. Objeto de muitas críticas de seus contemporâneos, é o próprio Rousseau que define a importância de redigir suas Confissóes, texto em que confessa, sim, seus defeitos, mas no qual também pode defender-se e explicá-los tant bien que mal. O incipit das Confissóes traz ao leitor uma série de informações que justificam a redação da obra, retrato da vida do homem Rousseau, empreendimento "jamais tentado por outro homem e que náo terá imitadores". Ele afirma querer mostrar a verdade da natureza de si mesmo e convida seu leitor a conhecer essa vida de erros e de acertos, de um homem por vezes desprezível e outras vezes generoso, desafiando seus leitores a se examinarem a si mesmos antes de ousarem julgar-se melhores do que o indivíduo ali retratado.

Je forme une entreprise qui n'eut jamais d'exemple et dont l'exécution n'aura point d'imitateur. Je veux montrer à mes semblables un homme dans toute la vérité de la nature; et cet homme, ce sera moi. Moi seul. Je sens mon coeur, et je connais les hommes. Je ne suis fait comme aucun de ceux que j'ai vus; j'ose croire n'être fait comme aucun de ceux qui existent. Si je ne vaux pas mieux, au moins je suis autre. (...) Je n'ai rien tu de mauvais, je n'ai rien ajouté de bon; et même s'il m'est arrivé d'employer quelque ornement indifférent, ce n'a jamais été que pour remplir un vide occasionné par mon défaut de mémoire. J'ai pu supposer vrai ce que je savais avoir pu l'être, jamais ce que je savais être faux. Je me suis montré tel que je fus ; méprisable et vil quand je l'ai été, bon, généreux, sublime, quand je l'ai été : j’ai dévoilé mon intérieur tel que tu l'as vu toi-même. Etre éternel, rassemble autour de moi l'innombrable foule de mes semblables; qu'ils écoutent mes confessions, qu'ils gémissent de mes indignités, qu'ils rougissent de mes misères. Que chacun d'eux découvre à son tour son coeur au pied de ton trône avec la même sincérité; et puis qu'un seul te dise, s'il l'ose : Je fus meilleur que cet homme-là. (ROUSSEAU, 1967: 121)

Essa escrita de Rousseau é por ele apresentada como um empreendimento que não teve predecessores e não terá imitadores. Ele tem, certamente, ciência de que não estava inaugurando o gênero autobiográfico, mas mostra suas Confissóes como uma iniciativa única, ao afirmar que não esconde nada e que pretende mostrar o homem - ele mesmo - na verdade de sua natureza. E quando Philippe Lejeune data do século XVIII o nascimento da autobiografia francesa, ele faz do século das Luzes o espaço temporal de origem da autobiografia moderna, ao mesmo tempo em que reconhece em Rousseau o pai do que hoje se conhece como autobiografia. 
Se algumas pesquisas querem fazer datar da Antiguidade a invenção do gênero, muitas delas não se afastam, no entanto, das conclusões de Philippe Lejeune. Em Linvention de l'autobiographie d'Hésiode à Saint Augustin (1993), que reúne os atos do segundo colóquio da equipe de pesquisa da Grécia pós-clássica da École Normale Supérieure à Paris, nota-se a preocupação em situar o evento sob a égide da pesquisa de Lejeune. "En référence aux travaux de Philippe Lejeune, l'accord s'est fait sur deux critères principaux: le caractère de récit rétrospectif global, couvrant la totalité d'une vie, et l'identité postulée entre l'auteur, le narrateur et le protagoniste du récit" (BASLEZ, 1993: 8). O título do livro e do colóquio poderia levar-nos a uma ideia equivocada de que os pesquisadores apresentam ali a Antiguidade como o início da escrita autobiográfica. No entanto, há uma abordagem prudencial ao falar do gênero autobiográfico, preferindo-se termos como "dimensão autobiográfica" e buscando-se analisar a expressão autobiográfica e não o gênero em si. $^{2}$

Mas as "confissões" que nasceram nos últimos vinte anos demonstram a atualidade da preocupação em deixar sua vida por escrito. E cada dia mais. $\mathrm{O}$ medo do esquecimento, a busca de um reconhecimento por seus pares, a febre dos avatares e Facebook, enfim a configuração de nosso mundo contemporâneo é propícia para a produção (e recepção) de textos autobiográficos. Obviamente, o primeiro tipo de texto autobiográfico desse início do século XXI são as diferentes redes sociais que se multiplicam e proporcionam a publicação instantânea de diversas escritas do eu. São páginas profissionais com depoimentos pessoais em que o autor - homem de negócios, fotógrafo, advogado... - quer vender o seu produto, mas para fazê-lo não se furta a dizer como iniciou sua empresa, a postar fotos pessoais e a (re)criar uma imagem do profissional que pode interessar seu público leitor, possível clientela para seu produto. No entanto, temos também as muitas páginas pessoais desenvolvidas com os mais diferentes objetivos - justificadas por diferentes razóes, mas apresentando todas aparentemente o mesmo objetivo: falar de si mesmo, divulgar suas fotos pessoais, relatos de viagem, histórias familiares... Em meio a justificativas variadas, verifica-se a preocupaçâo de registrar sua vida, de guardar - ou expor - suas memórias. Não vemos nesses textos a preocupação das Confissóes - quer sejam as de Agostinho ou as de Rousseau. Atualmente, guardar essas memórias já não é também mais escrever um diário e guardá-lo em uma gaveta da escrivaninha, deixando-o inclusive inacessível aos demais membros da família. Hoje trata-se de escrever um diário sim - mais ou menos fictício - e publicá-lo desde sua primeira página, deixan-

\footnotetext{
${ }^{2}$ Buscam uma análise "non du 'genre' autobiographique, mais de l'expression, ou de la visée autobiographique” (BASLEZ, 1993: 13).
} 
do-o ao alcance de muitos leitores (inclusive, muitas vezes, ao alcance dos familiares e pessoas próximas).

Quando nos pautamos pelos estudos de Philippe Lejeune, reconhecemos o quanto sua dedicação ao estudo dos escritos autobiográficos contribuiu não apenas para que essa produção integrasse os meios acadêmicos, mas também o quanto seus estudos contribuíram para a manutenção de uma antiga prática em diferentes suportes, mesmo nesse mundo digital em que vivemos atualmente: a criação da APA - Association pour l'Autobiographie representa essa tentativa de dar um espaço para autobiografias que guardam o suporte papel e que ainda são frequentes no final do século XX e início do século XXI. Ele, que inicialmente se voltara para o estudo dos grandes autores de autobiografia, como Rousseau, Sartre e Leiris, repensa seu trabalho em princípio dos anos 1990 e se pergunta se é razoável estudar o gênero autobiográfico e deixar de lado os diários. ${ }^{3}$ Até porque os diários que eram estudados até então eram aqueles publicados - visto que a própria escrita de um diário é, em geral, uma prática escondida e aquilo que se escreve permanece secreto. Em 2007, há três milhóes de franceses que se dedicam à redação de um diário. Os formatos são variados, não são apenas os tradicionais cadernos; há quem escreva seu diário em formato digital, há os que acompanham seu jornal de objetos e pequenas "relíquias" da vida cotidiana. E é com esse novo olhar sobre o gênero autobiográfico, que Lejeune começa uma nova fase em seu trabalho. É com esse novo olhar que a APA foi criada em $1992 .{ }^{4} \mathrm{Em}$ seu livro Pour l'autobiographie, Lejeune conta como descobriu a existência de arquivos autobiográficos. Ele diz que, ao ler um artigo do jornal Le Monde, descobre a associação Vivre et l'Écrire e a massa de textos escritos por adolescentes que ela havia coletado. Tal descoberta lhe traz certa incredulidade:

C'est un article du Monde qui m'a alerté: "Cent mille textes d'adolescents" (28 mai 1987). L'association Vivre et l'Écrire, fondée en 1976 par Pierre de Givenchy, aurait suscité, recueilli des masses de textes d'adolescents. Chaque matin la boîte à lettres de l'association (...) serait pleine de «cinquante ou soixante grosses enveloppes..." J'ai bien lu: «un journal intime». Incrédulité: jamais je n'aurais envoyé le mien par la poste à une association. J'écris, je téléphone, j'y vais. (LEJEUNE, 1998: 31-32)

O que mais surpreende Lejeune é o fato de um diário ser enviado pelo correio para uma associação. Se a escrita de diários tem um lado de catarse,

\footnotetext{
${ }^{3}$ É Philippe Lejeune mesmo que o diz em diferentes momentos, como, por exemplo, na conferência "Lautobiographie", pronunciada em 26 de abril de 2007.

${ }^{4}$ A associação APA foi criada em 1992 e foi reconhecida como de interesse geral em 2006. É dirigida por um Conselho administrativo que se reúne três vezes por ano e seu presidente atual é Philippe Lejeune.
} 
ela representaria também um texto que se guarda sob sete chaves - às vezes, literalmente, como em certos diários providos de cadeado - para que não seja lido e que os segredos daquele que escreve fiquem guardados. Mas os adolescentes respondiam ao apelo da associação Vivre et l'Écrire e entregavam seus diários, demonstrando, muitas vezes, o desejo de serem lidos por outros. $\mathrm{O}$ final do século XX assiste ao nascimento desse tipo de associação que guarda, protege, divulga os arquivos autobiográficos e de certo modo anuncia esses novos escritos do "eu", textos publicados ainda na década de 90 e sobretudo a partir do início do século XXI, com o advento da internet. Os diários perdem em muito o seu lado secreto e ganham "visibilidade".

Ne faut-il pas du temps, pour qu'un écrit intime devienne un document d'archive? N'y a-t-il pas contradiction entre une écriture secrète et un tel dépôt, même "par pure confiance"? Ne peut-on supposer que ceux qui lèguent ainsi leur journal ne représentent qu'une catégorie particulière, plus... communicative, plus sensible à l'attrait d'une publication? Et n'aura-t-on pas quelque gêne à prendre connaissance en "voyeur", même autorisé, de ces textes écrits pour soi seul... (LEJEUNE, 1998: 34)

Hoje ${ }^{5}$ essa pergunta parece ultrapassada quando pensamos nos textos autobiográficos publicados online: estes não são diários escritos para ficarem em segredo. Trata-se, ao contrário, de um texto que já nasce público. E os leitores guardam, certamente, esse lado "voyeur", mas o voyeurismo atualmente parece também tão natural que não chega a constituir objeto de reflexão: ao andarmos pelas cidades somos filmados em toda a parte: na rua, no supermercado, nas praças, nos bancos. Ao ver televisão, muitos dos programas - aliás, de grande sucesso de público - são de "reality shows", com os mais diferentes temas. $\mathrm{O}$ advento da internet e dos "reality shows" revela um mundo em que todos podem publicar sua autobiografia - fictícia ou náo - e receber mesmo um eco dos leitores.

Em Les Pratiques culturelles des Français à l'ère numérique, Olivier Donnat revela que o sucesso dos blogs e sites pessoais, no entanto, não extinguiu a prática da redaçáo de diários. Ele também fala de uma clara preferência pelo uso do suporte papel, mesmo entre aqueles que têm acesso à Internet (DONNAT, 2009: 202-203).

\footnotetext{
${ }^{5}$ Philippe Lejeune considera em suas pesquisas também os textos publicados na internet, sobretudo em conferências e publicaçóes mais recentes. Mas já em 1998, ele caracteriza a rede mundial como um suporte no qual o escritor de autobiografia poderia publicar seu texto de modo a que esse não fosse lido por parentes e amigos, mas só por desconhecidos: "Par exemple: Internet. Il suffit de prendre un nom de code, et d'être le seul de son milieu à surfer sur le Web"(LEJEUNE, 1998: 229). Acredito que muitos conseguem divulgar na Internet sem se fazer conhecer e podem dificilmente ser "descobertos" pela família e amigos. Mas hoje é praticamente impossível ser o único de seu meio a surfar na Internet...
} 
E as práticas autobiográficas têm buscado também novos suportes, além das páginas da Internet. Temos como exemplo, na França, cineastas como Alain Cavalier ${ }^{6}$ que fazem filmes autobiográficos. No caso específico de Cavalier, ele parte de seus diários filmados - como Le Filmeur, em que o cineasta apresenta dez anos de sua vida em um filme de 100 minutos: os primeiros planos do filme datam de 1994 e as imagens finais foram filmadas em 2005. Também as histórias em quadrinhos tornou-se suporte de produção autobiográfica, como nas publicaçôes de Fabrice Neau, cuja obra o jornal Le Point situa na vaga autobiográfica que aparece na história em quadrinhos Francesa nos anos 1990, citando L'ascension du haut mal de David B. e Journal d'un album de Dupuy et Berberian (BRETHES, 2012).

Cabe ressaltar que o gênero autobiográfico, considerado por tanto tempo algo menor, exceção feita às memórias de escritores - textos literários escritos por literatos renomados que falam de sua vida, de sua obra, de sua época -, ganha no final do século XX um novo espaço de estudo: agora náo são mais somente as autobiografias literárias que despertam o interesse dos críticos. E também não é apenas Philippe Lejeune que se debruçará sobre os escritos do "eu" redigidos pelo comum dos mortais. Outro nome importante nesse campo, responsável também pelo avanço desses estudos, é Georges Gusdrof. Filósofo de origem judaica, Gusdorf esteve em campo de concentração durante a Segunda Guerra e parece ter sido essa experiência que o levou a se interessar pelos escritos autobiográficos. Ele tece várias críticas sobretudo aos primeiros escritos de Philippe Lejeune, ${ }^{8}$ além de ressaltar a importância dos escritos autobiográficos não literários. Analisando a autobiografia ainda no século XVIII, Gusdorf mostra não se tratar de uma produção que interessasse apenas à burguesia em ascensão. Ele revela que o gênero pode ser encontrado também junto a pessoas do povo (1991). Para Gusdorf e Lejeune, os escritos do eu que não têm um valor literário reconhecido são também muito significativos e o primeiro acusava os críticos literários de ignorarem essa produção acusação inicialmente voltada para o próprio Philippe Lejeune que só passa a se preocupar com os textos autobiográficos não literários nos anos 1990.

\footnotetext{
${ }^{6}$ Em conferência proferida em abril de 2007, Philippe Lejeune cita os exemplos de Alain Cavalier e Fabrice Neau que retomamos aqui.

${ }^{7}$ Seu primeiro filme autobiográfico foi Ce Répondeur ne prend pas de messages, de 1978, e o segundo La Rencontre de 1996. E depois de Le Filmeur, ele ainda lança Irène (2009) que aparentemente será o último da série de seus filmes autobiográficos.

${ }^{8}$ Ele critica, por exemplo, o fato de Lejeune ver no século XVIII as origens da autobiografia. Em Les écritures du moi, Gusdorf traz à tona diversos aspectos para desacreditar as afirmativas de Lejeune: o fato de que este teria ignorado os textos autobiográficos escritos na Inglaterra e Alemanha antes do século XVIII e considerado toda essa produção anterior como uma pré-história da autobiografia.
} 
A análise da redação, do processo de escrita, da motivação, do percurso dos diferentes autores de autobiografia pode trazer muitas informaçóes sobre essa prática e para a compreensão de sua importância para o homem. Lembremos que escrever sobre si mesmo é, muitas vezes, uma prática aconselhada por médicos e psicólogos e pode ajudar no tratamento terapêutico. A APA - e outras associaçóes semelhantes, como a APA belga, ${ }^{9}$ fundada em 2002 - tem o cuidado de proporcionar leitores para os textos que lhe foram confiados e os autores recebem um feedback desses leitores voluntários. Não se trata de uma crítica literária ou julgamento de leitura, mas um retorno sobre o que foi lido, sobre a experiência de vida escrita e compartilhada. Muitas vezes, inclusive, é esse retorno que buscam os que entregam seus textos à APA e o leitor pode ocupar, por vezes, o lugar de confidente ou psicoterapeuta que, de certo modo, reconforta quem escreve e propicia a sobrevivência dessa produção. A APA tem também em sua revista La Faute à Rousseu, que existe há mais de 20 anos, ${ }^{10}$ um espaço para o estudo do gênero.

A preocupação com o arquivamento desse material é essencial para o estudo do gênero autobiográfico, além de propiciar também a valorização desse tipo de produção. Pessoas que têm tal material e não queiram se desfazer dele podem, assim, deixar seus manuscritos cuidados para estudos posteriores, sem necessariamente publicá-los ou permitir sua leitura em um prazo curto. Com certeza, muitos diários e outros tipos de manuscritos autobiográficos se perderam antes que nascesse uma iniciativa desse tipo - e outros tantos se perderão, certamente. Mas a Associação já tem um arquivo considerável e continua aumentando seu acervo, sempre solicitando textos e tendo a grata satisfação de recebê-los.

Se, de um lado, tranquiliza-nos a escrita phármakon que parece assegurar-nos o controle sobre nosso passado ao ser este transposto para o papel, de outro, assusta a perspectiva da leitura que outros farão de nossos textos - em um futuro mais ou menos distante. A APA francesa, assim como também a belga, propóe-se a arquivar escritos autobiográficos cujos autores não desejam ser lidos por um certo período de tempo. O cuidado em arquivar os textos e respeitar o desejo de náo publicação dos autores revela duas preo-

\footnotetext{
${ }^{9}$ Proposta definida no site da APA belga: Chaque document fait l'objet d'un compte rendu de lecture en sympathie. Il s'agit de rendre compte du contenu et des intentions de l'œuvre, sans jugement et dans le plus grand respect de l'auteur. Ce compte rendu est envoyé au donateur et/ou à l'auteur, puis publié dans notre garde-mémoire, la revue annuelle De temps en temps. (APA-Bel)

${ }^{10}$ Quando entrevistado por Laurence Santantonios, Lejeune explica o título de sua revista: "Notre numéro zéro, photocopié, avait pour titre Pour l'autobiographie. C'était clair, mais plat. Notre ami Philippe Artières a proposé La Faute à Rousseau. Adopté ! C'est une allusion à la chanson de Gavroche dans Les Misérables, et ça veut dire, bien sûr, que l'autobiographie c'est la faute à Rousseau, à cause des Confessions. Double clin d'œil, qui peut égarer. On nous prend parfois pour une revue " dix-huitièmiste ». Au Salon de la revue on nous met à côté de Voltaire." (SANTANTONIOS, 2014).
} 
cupaçóes primordiais: a primeira, a confiança necessária para depositar nas mãos de uma associação a história de sua vida e a dificuldade que ainda existe em tornar pública essa vida - mesmo em um momento em que quase todos parecem atraídos pela ideia de publicar sua história. Em segundo lugar, por parte da associação, também fica clara a necessidade de propiciar um espaço para esses textos que muitas vezes se perdem nos sótãos das casas - ou, mais modernamente, em HDs ou pen-drives descartados - e vêm a ser destruídos.

$\mathrm{O}$ interesse em guardar esse material está exatamente na série de estudos que se poderá fazer a partir da análise de um corpus como esse - que pode ser considerado como corpus de um estudo linguístico e literário, mas que vai além das fronteiras do mundo das Letras, podendo interessar a outras áreas como a sociologia, a psicologia, a história. O bloquinho de notas em que rascunhamos nossas questóes existenciais pode vir a ser o ponto de partida de um futuro brilhante pesquisador para a realização de novas terapias ou de novas reflexões sobre a tecnologia e o homem do século XXI. ${ }^{11}$

As pesquisas de Lejeune avançam ao mesmo tempo em que ele retoma seus trabalhos anteriores e revê suas afirmaçóes por causa de elementos novos que encontra na produção autobiográfica ou mesmo devido às novas tecnologias que impulsionaram o gênero e trouxeram novo formato para vários escritos autobiográficos. A própria necessidade de uma assinatura no texto autobiográfico para que o personagem possa ser aproximado do autor do texto, que aparece como essencial no início do trabalho de Philippe Lejeune, será revista posteriormente. Em Moi aussi, o autor faz a seguinte reflexão:

Cela se voit bien quand j'en arrive à l'autobiographie anonyme. Au lieu de procéder à une analyse plus poussée des différents cas possibles (et des différentes réactions possibles des lecteurs), je me bloque (...). (LEJEUNE, 1986: 17)

Durante minha pesquisa de doutorado, senti-me particularmente curiosa diante desse comentário feito em Moi aussi, quando Lejeune reconhece seu bloqueio inicial ao considerar a autobiografia anônima. E foi em uma conferência feita em novembro de 2003, em Bruxelas, que ele explicou como poderia considerar então certos textos anônimos como representantes do gênero autobiográfico. Sua resposta foi surpreendente: no caso específico a que ele se referia em Moi aussi, tratava-se de manuscritos arquivados em um hospital. Esses manuscritos não tinham a finalidade de publicação, mas representavam uma etapa no tratamento de alguns pacientes. Parte da terapia consistia

\footnotetext{
${ }^{11}$ Tendo falado no presente artigo sobre a APA francesa e mencionado rapidamente a APA belga, não posso deixar de mencionar que, em nosso país, também temos pelo menos uma Associação Brasileira de Pesquisa (Auto)Biográfica. Trata-se da BIOgraph, "uma Associação Científica sem fins econômicos, registrada como pessoa jurídica de direito privado, fundada em 16/10/2008”. É uma associação mais recente e que (ainda) não tem a preocupação de constituir um arquivo autobiográfico.
} 
em escrever sua vida, episódios de sua vida. Essa escrita terapêutica pode - e deve - ser analisada sob um ponto de vista outro que uma autobiografia que se pretende literária e cuja pretensão seria a publicação. No entanto, tais textos são claramente representantes do gênero autobiográfico e podem, eventualmente, trazer nova luz para os estudos das escritas do "eu".

Falar, porém, desse histórico dos estudos do gênero autobiográfico na França partindo do gigantesco trabalho de Philippe Lejeune, leva-nos necessariamente a repensar o que vem acontecendo com toda a publicaçáo feita na Internet e de que modo esse material poderá também contribuir para futuras pesquisas, visto que o que está na Internet hoje pode ser apagado amanhã e a APA só arquiva textos em suporte papel (com raras exceçóes, como todo um conjunto de textos confiados em formato digital, mas que permanecem sem leitores porque continuam apenas na versão gravada em CD). ${ }^{12}$ Em seus livros mais recentes, Le journal intime: histoire et anthologie (2006) e Autogenèses: Brouillons de soi 2 (2013), o autor traz como elemento central o formato online. Suas reflexôes sobre como essas obras de publicação imediata parecem distanciar-se da possibilidade de transmissão para as geraçôes futuras são muito interessantes. A lei francesa sobre os direitos autorais foi modificada em 2006 e os depósitos feitos na Internet são também objeto de direitos autorais. Para salvaguardar esse patrimônio, a Bibliothèque Nationale de France e o Institut National de l'Audiovisuel fazem de 6 em 6 meses a gravação de toda a produção da Internet francófona. Trabalho hercúleo, desconhecido da maior parte da população, mas que permitirá, futuramente, acesso a um acervo digital que desapareceria, se não fosse por essa medida.

E nós? Estaríamos dispostos a entregar nosso diário a uma associação? Ou publicaríamos nosso texto na Internet, permitindo a conhecidos e estranhos a aproximação a um passado que agora não nos pertence mais? Seria esse diário uma ficção de um passado, uma autoficção, um arranjo da narrativa de um passado como a narrativa de viagens a países que ninguém conhece? $\mathrm{O}$ medo de que sejamos relegados à morte pelo esquecimento ou uma necessidade narcisista de exposiçấo do "eu" podem mover-nos a fazer de um simples diário testemunho para as próximas geraçóes e dessa herança autobiográfica material para o estudo de um dado momento histórico.

\footnotetext{
12 "Ce que voyant, je lui ai suggéré de déposer à l'APA à la fois son journal et son orphelinat, il l'a fait, mais uniquement sous forme de $\mathrm{CD}$, sans réaliser la copie papier que je lui avais suggéré d'adjoindre, et que nous n'avons pas faite non plus. Ces CD sont donc l'unique trace publique qui subsiste des journaux pionniers des années 1999-2000" (LEJEUNE, 2012: 7).
} 


\section{Referências bibliográficas}

Association pour l'Autobiographie et le patrimoine autobiographique. Disponível em: <http://autobiographie.sitapa.org/informations-pratiques/article/qui-sommesnous>. Acesso em: 14 de maio de 2016.

Association du patrimoine autobiographique APA-Bel. Disponível em: <http://www. apabel.be/index.php?ption=com_content\&view=article\&id=74\&Itemid=114> Acesso em: 14 de maio de 2016.

BASLEZ, Marie-Françoise et alii. L'invention de l'autobiographie d'Hésiode à Saint Augustin. Paris: Presses de l'École Normale Supérieure, 1993.

BRETHES, Romain. Fabrice Neaud, l'enfant terrible de la BD française. 2012. Disponível em: <http://www.lepoint.fr/livres/fabrice-neaud-l-enfant-terriblede-la-bd-francaise-28-01-2012-1424747_37.php>. Acesso em: 14 de maio de 2016.

BROWN, Peter. Santo Agostinho, uma biografia. Rio de Janeiro: Record, 2005.

DONNAT, Olivier. Les Pratiques culturelles des Français à l'ère numérique, Enquête 2008, Paris: La Découverte/Ministère de la culture et de la communication, 2009.

GUSDORF. Les écritures du moi. Paris: Odile Jacob, 1991.

LEJEUNE, Philippe. L'Autobiographie en France. Paris: Colin, 1971.

- Le pacte autobiographique. Paris: Seuil, 1975.

. Pour l'autobiographie. Paris: Seuil, 1998.

. Moi aussi. Paris: Seuil, 1986.

. Les Brouillons de soi. Paris: Seuil, 1998.

. L'autobiographie et les nouveaux outils de communication. Conferência pronunciada em Lyon, 6 de outubro de 2012. Disponível em: <http://www. autopacte.org/nouveauxoutils.pdf>. Acesso em: 14 de maio de 2016.

. L'autobiographie. 2007. Conferência. Disponível em: <https://www.canal-. tv/video/universite_de_tous_les_savoirs_au_lycee/l_autobiographie_philippe_ lejeune.1504>. Acesso em: 14 de maio de 2016.

ROUSSEAU. Euvres complètes. Vol. 1. Paris: Ed. Seuil, 1967.

SANTANTONiOs, L. La Faute à Rousseau, Revue de l'autobiographie. 2014. Disponível em: <http://www.entrevues.org/gros-plan/faute-rousseau-revuelautobiographie/>. Acesso em: 14 de maio de 2016.

Marilia Santanna Villar é professora da Universidade Federal do Rio de Janeiro (UFRJ), com interesse na área de literatura francófona, autobiografia e teatro simbolista. Doutora pela Universidade Católica de Louvain (Bélgica) e Mestre pela Universidade Federal do Rio de Janeiro (UFRJ).

E-mail: villar.marilia@gmail.com

Recebido em: 15/05/2016 Aprovado em: 30/07/2016 